\title{
O Trabalho do Cientista nos Cartuns de Sidney Harris: Um Estudo sob a Perspectiva da Sociologia da Ciência
}

\author{
The work of scientists at Sidney Harris's cartoons: a study from the \\ sociology of science perspective
}

Fernanda Resende Roxael, Natália de Paiva Diniz e Jane Raquel Silva de Oliveira

Resumo: A educação científica deve possibilitar uma melhor compreensão do trabalho do cientista e do processo de construção social da ciência. Neste trabalho, buscamos investigar um recurso didático alternativo que possa ser utilizados nessa perspectiva: os cartuns de cientistas criados por Sidney Harris. O objetivo desta pesquisa foi analisar alguns aspectos da sociologia da ciência presentes nesses cartuns que abordam questões ligadas ao trabalho de cientistas. Foram adotados como referencial teórico alguns aspectos da sociologia da ciência descritos na obra A vida de laboratório de Bruno Latour e Steve Woolgar. Foram selecionados 10 cartuns que apresentassem imagens de cientistas em diversas situações do cotidiano da ciência ou imagens que abordam questões ligadas ao trabalho de cientistas. Foi realizado um inventário denotativo dos elementos que constituem cada cartum. Em seguida, fez-se uma análise de significação conotativa desses elementos, buscando agrupar cada cartum nas categorias analíticas delineadas a partir do referencial teórico. Os resultados revelaram que, nos cartuns, é possível observar algumas características da prática da ciência como o trabalho coletivo, a valorização das publicações, a manutenção do ciclo de credibilidade e a presença feminina na ciência.

Palavras-chave: natureza da ciência, sociologia da ciência, cartuns, divulgação científica, Sidney Harris.

\begin{abstract}
Science education should enable a better understanding about the work of scientists and the social construction of science. In this work, we investigate an alternative teaching tool that can be used for this purpose: the cartoons of scientists created by Sidney Harris. The purpose of this study was to analyze some aspects of the sociology of science present at Sidney Harris's cartoons showing issues relating to the work of scientists. Aspects of the sociology of science described in the book The Laboratory Life (Latour and Woolgar) were adopted as the theoretical framework. We selected 10 cartoons that showed images of scientists in several situations of their daily routine on science, or images that showed issues relating to the work of scientists. A denoting inventory of the elements of each cartoon was performed. Then was made a connotative meaning analysis of these elements, gathering each cartoon in analytical categories outlined from the theoretical framework. The results show that we can see in cartoons some practical characteristics of science as the collective work, the publications value, the scientist credibility cycle and the presence of women in science.
\end{abstract}

Keywords: nature of science, sociology of science, cartoons, popularization of science, Sidney Harris.

Fernanda Rezende Roxael (fer_roxael@ hotmail.com), aluna do curso de Licenciatura em Química da Universidade Federal de Itajubá (UNIFEI). Itajubá, MG - BR. Natália de Paiva Diniz (nat.dpaiva@ gmail.com), aluna do curso de Licenciatura em Química da UNIFEI. Itajubá, MG - BR. Jane Raquel Silva de Oliveira (janeraquel@unifei.edu.br), graduada em Farmácia pela Universidade Federal do Maranhão (UFMA), mestre em Ciências pela Universidade de São Paulo (USP), doutora em Química pela Universidade Federal de São Carlos (UFSCar), é docente da UNIFEI. Itajubá, MG - BR.

Recebido em 11/10/2014, aceito em 03/02/2015 
"É preciso compreender o carácter social do desenvolvimento científico, $[\ldots .$.$] que o trabalho dos$ homens e mulheres da ciência - como qualquer outra actividade humana - não tem lugar à margem da sociedade em que vivem, e se vê afectado, logicamente, pelos problemas e circunstâncias do momento histórico, do mesmo modo que sua acção tem uma clara influência sobre o meio físico e social em que se insere. Assinalar isto pode parecer supérfluo, no entanto, a ideia de que fazer ciência é uma tarefa de 'génios solitários' que se encerram numa torre de marfim, desconectando-se da realidade constitui uma imagem tópica muito estendida e que o ensino lamentavelmente não ajuda a superar." (Cachapuz et al., 2005, p. 61)

As palavras apresentadas por Cachapuz e colaboradores (2005) reforçam a opinião e os resultados de outros pesquisadores sobre as visões que algumas pessoas têm sobre ciência e sobre as atividades dos cientistas (Kominsky; Giordan, 2002).

Segundo Costa (2013), em uma busca rápida na internet por imagens referentes ao termo cientista, é fácil perceber um pouco do imaginário que parte da sociedade tem sobre a atividade científica e sobre aqueles que a ela se dedicam. Para muitos daqueles não ligados à vida acadêmica, por exemplo, o cientista é retratado, em geral, como louco, desleixado, excêntrico e genial. A ciência consequentemente é vista como algo exótico, difícil e para poucos. Essas concepções tornam-se um mito e, como todo mito, podem induzir certos comportamentos como o distanciamento das questões ligadas à ciência.

Uma pesquisa sobre percepção pública da ciência que teve como objetivo levantar informações sobre interesse, grau de informação, atitudes, visões e conhecimento que os brasileiros têm da ciência e tecnologia revelou também alguns cenários que merecem atenção: se por um lado $65 \%$ dos entrevistados manifestaram ter interesse em temas da ciência e tecnologia, um percentual bem menor (25\%) indicou não se informar com frequência sobre tais assuntos, sobretudo pelo fato de não os entender. Além disso, poucas pessoas leem sobre ciência em jornais (14\%) ou revistas (13\%). Outro dado notável é o pequeno percentual de entrevistados (18\%) que soube indicar uma instituição que se dedica a fazer pesquisa científica no país. O estudo também mostrou alguns conhecimentos e percepções que as pessoas têm sobre a atividade científica. Para muitos dos entrevistados (38\%), os cientistas são pessoas inteligentes que fazem coisas úteis à humanidade. Além disso, ainda permanecem algumas concepções de cientista como uma pessoa excêntrica que fala de forma complicada e que se interessa por temas distantes da realidade das pessoas (Brasil, 2010).

Nesse contexto, autores como Gil-Pérez e Vilches (2005) apontam que uma educação científica básica deve contemplar, além de conhecimentos da ciência e suas aplicações, saberes e técnicas, a abordagem das questões sociais, econômicas, políticas e éticas que permeiam sua prática, isto é, discussões sobre os aspectos filosóficos e sociológicos das atividades típicas da comunidade científica. Os Parâmetros Curriculares Nacionais para o Ensino Médio (Brasil, 1999), embora não coloquem de forma muito explícita a abordagem de conteúdos relacionados à filosofia da ciência no currículo escolar, mencionam a importância de os estudantes compreenderem as ciências como construções humanas, as relações entre o desenvolvimento científico e as transformações da sociedade, o impacto da tecnologia nos processos de produção e na vida social etc.

Conforme Díaz (2005), é primordial reconhecer e entender que o conhecimento científico é importante para a formação de cidadãos, pois isso contribui para que se amplie a capacidade de compreensão e de atuação no meio sócio-histórico em que nos situamos. Nesse contexto, deve-se adquirir uma compreensão adequada da natureza da ciência, o que, por sua vez, implica também conhecer seu funcionamento interno e externo, como se constrói e se desenvolve o conhecimento que ela produz, os métodos utilizados para validar esse conhecimento, os valores implícitos ou explícitos nas atividades da comunidade científica, os vínculos com a tecnologia, as relações com a sociedade e com o sistema técnico-científico e as contribuições desse conhecimento para a cultura e para o progresso da sociedade.

No entanto, nem sempre o professor está preparado para atuar dentro dessa perspectiva, devido, em muitos casos, às carências em seus processos formativos. Alguns estudos têm apontado que muitos professores de ciências ainda mantêm uma série de visões inadequadas sobre o fazer científico, o que se reflete na maneira como ele apresenta a ciência aos estudantes, podendo fomentar ainda mais visões equivocadas sobre esta (Carvalho; Gil-Pérez, 2003). Além disso, o principal recurso didático empregado pelos professores na organização e seleção de conteúdos de suas aulas é o livro didático, e este nem sempre traz conteúdos direcionados a uma abordagem de aspectos sociais e filosóficos da ciência.

Diante de tais cenários, vários pesquisadores têm se empenhado em estudar outros materiais e recursos didáticos que possam ser utilizados para tratar de questões dessa natureza, tais como: textos originais de cientistas, materiais de divulgação científica, ilustrações, biografias e muitos outros. Dentre esses, um dos mais explorados são os materiais de história da ciência, os quais podem auxiliar o professor a discutir com os alunos como a ciência é produzida, passando ao mesmo tempo a imagem do cientista e os valores sobre a ciência. Isso pode fazer com que os alunos tenham uma visão diferente (e talvez mais correta) do cientista de épocas passadas, contextualizando-o com as limitações da época, o contexto sociocultural e histórico e a importância que eles tiveram para o desenvolvimento de conceitos hoje utilizados (Oki; Moradillo, 2008).

Os textos de divulgação científica, ainda que timidamente, também têm se revelado como um recurso útil para tal finalidade. O estudo realizado por Oliveira (2013), por exemplo, 
mostrou outra maneira de evidenciar algumas práticas da ciência em construção: os artigos da seção Ciência da revista Pesquisa FAPESP. Na análise realizada com alguns desses textos, foram identificadas informações e marcas linguísticas que evidenciam vários aspectos da dinâmica da ciência como: alianças entre pesquisadores e instituições, ênfase às aplicações da pesquisa na esfera social e econômica, preocupações com patentes e financiamentos, destaque à produtividade acadêmica (publicações em revistas científicas da área), presença de hipóteses e incertezas que surgem durante as pesquisas, indicação de limitações dos estudos etc.

Nesta pesquisa, levantamos a hipótese de que cartuns sobre ciência e sobre cientistas possam também oferecer mais um caminho para a compreensão de alguns aspectos dessa natureza.

$\mathrm{Na}$ tentativa de estabelcer uma definição para cartuns e outros tipos linguísticos como quadrinhos, charges, tiras e mangás, Moretti (2006, p. 1) afirma que "não é fácil estabelecer uma diferença definitiva entre essas formas de arte", embora alguns autores as classificam de acordo com alguma característica peculiar. Conforme Batista (2011), a charge é um texto de humor que, por meio de ilustração, aborda temas do noticiário e trabalha com figuras reais caricaturadas. Palavra de origem francesa que significa também carga, a charge trabalha com o exagero dos traços do caráter de alguém ou de algo. A charge e o cartum são muito parecidos, pois ambos têm, em suas características, o senso crítico e podem ser acompanhados ou não de legenda. A diferença é que o cartum não está vinculado a um fato do noticiário jornalístico e sim a uma situação corriqueira, é atemporal, não está vinculado ao contexto específico de uma época, ficando fácil diferenciá-lo por essa abordagem, enquanto a charge geralmente é datada e localizada geograficamente.

Já os quadrinhos apresentam uma perspectiva mais ampla, podem ser críticos, esotéricos, infantis, adultos. Eles têm personagens e elenco fixos, narrativa sequencial em quadros numa ordem de tempo onde um fato se desenrola por meio de legendas e balões com texto pertinente à imagem de cada quadrinho. A história pode se desenvolver em uma tira, uma página ou várias (revista ou álbum). Para se caracterizar uma história em quadrinho, são necessários no mínimo dois quadrinhos (ou cenas). Se for apenas um quadro, ela se torna uma tira. Algumas tiras satirizam aspectos econômicos e políticos do país, embora não sejam tão datadas como a charge. Apesar da semelhança, isso não a torna um cartum (Moretti, 2006).

Os mangás originalmente referem-se a todas as histórias em quadrinhos produzidas no Japão. No entanto, como não faz mais sentido classificar fenômenos culturais considerando somente o território, este passou a se referir a uma espécie única de história em quadrinhos que reúne estilo, traço, técnica, desenho, linguagem e tema próprios (Tancini; Hoff, 2012).

$\mathrm{O}$ uso de quadrinhos, tiras, charges e cartuns tem se tornado cada vez mais expressivo no contexto educacional, tanto em materiais didáticos como também em provas de processos seletivos, sobretudo pelo fato de que essa forma de representação faz parte da rotina de muitas pessoas, uma vez que é bastante divulgada nos meios de comunicação. Por se configurar em uma leitura agradável e envolvente, os alunos podem achá-la prazerosa, o que facilita seu emprego nas situações de ensino e aprendizagem.

Tais elementos visuais, como quadrinhos, cartuns, charges e tantos outros, constituem um texto não verbal e, portanto, são capazes de transmitir significados. Alguns desses elementos também podem estar associados a textos verbais. Segundo Joly (1996), a imagem pode ilustrar um texto verbal ou o texto pode esclarecer a imagem na forma de um comentário. Outro aspecto importante a se considerar é que a linguagem visual não é uma linguagem universal, mas sim culturalmente localizada. Tanto a produção da imagem pelo enunciador quanto o significado a ela atribuído pelo leitor são dependentes do contexto social e histórico.

Neste trabalho, lançamos o olhar sobre os cartuns e mais especificamente sobre aqueles produzidos por Sidney Harris, um artista que, embora não tenha formação na área de ciências, consegue tocar em pontos essenciais desta. Segundo Reynol (2008, p. 15),

[...] a desenvoltura com que Harris trata da práxis científica, sem ser cientista, é surpreendente. Aborda com propriedade temas como a subjetividade do pesquisador na escolha dos dados, a ditadura dos paradigmas e a relação da pesquisa com suas fontes de financiamento. A qualidade de sua produção o fez o mais requisitado cartunista científico dos EUA.

A carreira de Harris começou desde que resolveu enviar alguns de seus trabalhos para a revista American Scientist. Desde então, seus cartuns começaram a aparecer em publicações científicas como Science e Discovery, bem como em outros gêneros como o The New Yorker e The Wall Street Journal. Acredita-se que a obra dele seja bastante democrática, sendo acessível tanto ao público em geral quanto a cientistas (Reynol, 2008).

Qualquer que seja o recurso ou veículo para fornecer uma visão mais humanística da ciência, é necessário revelá-la de forma mais ampla, contemplando discussões sobre suas bases epistemológicas e suas relações com as esferas sociais, políticas e econômicas. Isso requer a abordagem não somente dos produtos da ciência, mas também um olhar para seu processo de construção.

Essa dupla forma de compreender a ciência é citada por Bruno Latour (2000): de um lado, podemos olhar para uma ciência pronta, acabada, com suas caixas-pretas fechadas; de outro, para uma ciência em construção, ainda repleta de debates e controvérsias. É por esse último perfil que ele delineia seus estudos na área de sociologia da ciência, marcadamente por vieses etnográficos, descortinando algumas práticas contemporâneas da ciência, revelando-a como um processo social caracterizado por incertezas, riscos, relações políticas e econômicas. 
Segundo Vianna e Carvalho (2001), os estudos de Latour possibilitam o entendimento de como os cientistas agem e como produzem o conhecimento. Favorece ainda uma análise crítica de questões como a dinâmica da construção social da ciência e da tecnologia, o cotidiano dos cientistas dentro e fora do laboratório, as relações entre o laboratório fechado e a comunidade aberta ao seu redor, o jogo de interesses políticos, o financiamento das pesquisas, dentre muitos outros aspectos usualmente distantes dos manuais escolares e do que muitas atividades de divulgação científica se propõem a apresentar.

É importante ressaltar que o estudo de Latour possui natureza etnográfica, que provém de seu acompanhamento diário dos pesquisadores dentro e fora do laboratório. No livro A vida de laboratório, Latour e Woolgar (1997) apresentam uma pesquisa minuciosa em antropologia da ciência, buscando relatar os diálogos entre os profissionais, telefonemas, dados, inquietações dos cientistas, sempre observando e compreendendo os fatores que influenciam no desenvolvimento da ciência.

Pesquisas mostram algumas contribuições que esse livro gerou para a compreensão de aspectos da comunidade científica por estudantes de química. Zanon, Almeida e Queiroz (2007) verificaram que os estudantes de um curso superior de química, cujas concepções prévias remetiam à noção de que ser cientista é estar no laboratório, passaram a reconhecer suas limitações, sobretudo no que se refere à produção de artigos científicos e às relações socioeconômicas envolvida na produção do conhecimento.

Considerando a importância de se inserir, no contexto da educação em ciência, a abordagem de aspectos relacionados à filosofia e sociologia da ciência, o objetivo deste trabalho foi analisar alguns cartuns de Sidney Harris que abordam questões ligadas ao trabalho de cientistas sob a ótica da sociologia de Bruno Latour, no intuito de tecermos algumas discussões sobre o uso de recursos dessa natureza na educação científica.

\section{Aspectos da sociologia da ciência na obra A Vida de Laboratório}

O livro A vida de laboratório de Latour e Woolgar (1997) tornou-se um clássico dos chamados estudos sociais na ciência. Embora Latour tenha sido convidado para realizar uma análise epistemológica, foi o olhar e o método da antropologia que o transformou no sociólogo da ciência que foi ao campo empreender um estudo empírico detalhado das atividades cotidianas dos cientistas em seu habitat natural (Kropf; Ferreira, 1998).

Publicado originalmente em 1979, o livro apresenta o estudo etnográfico realizado pelos autores analisando o cotidiano de pesquisadores do laboratório do professor Roger Guilhemin no Instituto Salk de San Diego. O acompanhamento dos membros do laboratório foi realizado durante dois anos, permitindo que os autores relatassem a vida de laboratório, observando os diálogos entre os profissionais, sua comunicação impressa, suas inquietações e comportamentos, além de vários aspectos econômicos e sociais como as preocupações com financiamentos, a credibilidade do pesquisador no meio acadêmico, dentre outras questões usualmente ocultas nos artigos científicos, mas que constituem a construção da ciência.

Alguns dos aspectos que consideramos relevante para os fins desta pesquisa foram organizados em categorias e descritos a seguir:

\section{O trabalho na ciência é coletivo}

Um ponto importante, destacado pelos autores, é que o trabalho não é individual e sim coletivo, ou seja, a ideia difundida de que o desenvolvimento científico depende exclusivamente do esforço individual de gênios isolados em seus laboratórios pode ser desmitificada por essa análise sociológica.

Os autores também explicitam na obra a intensa rede de colaboração entre os pesquisadores. Ressaltam que o trabalho coletivo rende muito mais frutos ao pesquisador, pois quanto mais contatos ele tiver no meio, mais recursos ele pode vir a ter, que será convertido em insumos, que lhe fornecerá dados e argumentos, resultando em um artigo publicado, gerando mais reconhecimento e credibilidade. A produção de novos fatos depende, em muitos casos, da manutenção dessa rede.

\section{O trabalho na ciência não ocorre apenas no laboratório}

Latour e Woolgar (1997) revelam também que a produção do conhecimento científico não acontece apenas nas bancadas dos laboratórios. Os autores fazem questão de mostrar a planta do laboratório, que se divide basicamente em escritório, biblioteca e bancadas, ou seja, o trabalho do cientista não se resume em processos, análises e manuseio de equipamentos, mas também envolve a produção de relatórios, documentos e artigos, além de suas atividades administrativas. Ao detalhar os papéis dos atores que fazem parte de todo esse processo, eles ainda ampliam a visão de comunidade científica e destacam que "as pessoas que estão realmente fazendo ciências, não estão todas no laboratório: ao contrário, há pessoas no laboratório porque muitas mais estão fazendo ciências em outro lugar" (p. 267). Entendem esses espaços de produção da ciência como uma imbricada rede composta por diversos elementos, instâncias, interesses, parcerias, procedimentos, saberes etc., formadas por séries heterogêneas de elementos humanos e não humanos.

\section{O trabalho na ciência envolve um sistema de inscrição literária}

Eles ainda afirmam que o laboratório é um sistema de inscrição literária, em que as etapas intermediárias ocorrem na forma de relatórios elaborados pelo corpo técnico, que registra os acontecimentos, analisa, compara dados e os compila na 
forma do produto final - $\mathrm{o}$ artigo. A produção literária é parte essencial para o trabalho do cientista, e ela acontece de diversas formas: desde as rotulações constantes na parte das bancadas até a elaboração dos artigos nos escritórios. Dessa forma, utiliza-se de um elemento capaz de transmitir em escrita a matéria utilizada para pesquisa, os chamados inscritores.

Os inscritores são uma das ferramentas utilizadas para a produção dos artigos, sendo estes considerados um produto fabricado nos laboratórios e a finalidade essencial da atividade ali desenvolvida. Os aparelhos diversos que produzem resultados, esquemas em folhas de papel, a identificação e organização das amostras, materiais e reagentes, fichários e arquivos contendo dados de testes também fazem parte da inscrição literária.

\section{A publicação de artigos é uma tarefa essencial no trabalho do cientista}

Outro ponto bastante enfatizado pelos autores é a importância das publicações dentro da comunidade científica: para o pesquisador, "[...] a produção de artigos é a finalidade essencial de sua atividade" (Latour; Woolgar, 1997, p. 70). O reconhecimento e o prestígio do pesquisador estão diretamente ligados à sua produção acadêmica. Essa produção se reflete também no interesse que os outros demonstram no seu trabalho, no fato de que ele seja mais facilmente acreditado ou ouvido com maior atenção pela comunidade, que seus dados sejam mais confiáveis, formando um conjunto mais digno de crédito.

\section{O trabalho do cientista envolve o investimento em um ciclo de credibilidade}

Muitas das afirmações dos autores sobre o trabalho na ciência é resumido no que denominaram ciclo de credibilidade do cientista, por meio do qual os pesquisadores conseguem mais investimentos para seus trabalhos.

"O caráter essencial desse ciclo é o ganho de credibilidade que permite o reinvestimento - e um ganho posterior de credibilidade. Por conseguinte, não há outro objetivo último do investimento científico além do desdobramento contínuo de recursos acumulados. É nesse sentido que relacionamos a credibilidade dos pesquisadores a um ciclo de investimento de capital." (Latour; Woolgar, 1997, p. 220)

\section{O trabalho na ciência envolve gerenciamento de recursos}

Gerenciar um laboratório e seus recursos também é uma das tarefas de um pesquisador. Mesmo sendo uma parte burocrática do processo de se fazer ciência, a questão econômica é uma das maiores preocupações em um laboratório. Sem o investimento e o apoio financeiro para manter ou ampliar sua pesquisa, o cientista não pode comprar materiais, equipamentos e insumos para prosseguir com seus projetos.

Para se ter investimento disponível, é necessário levar em consideração o efeito de retorno, a política financeira da região, a publicação e a recepção do artigo. Os investimentos são reembolsados indiretamente com publicações e com a produção de fatos. O lucro, para quem investe, pode ser obtido sob a forma de dados a serem mencionados como apoio a um argumento desenvolvido em um artigo e também, é claro, em valor econômico.

\section{A referência à literatura é recorrente no trabalho do cientista}

Um ponto relevante abordado por Latour e Woolgar (1997) são as conversas formais, aquelas nas quais os indivíduos se referem ao outro de maneira perfeitamente estruturada, como aparecem nos artigos, e as conversas informais que, segundo eles, são as mais utilizadas, tendo como referência a literatura publicada:

"Na maior parte do tempo, mesmo quando se fala ao telefone, discutem-se documentos, seja para combinar a colaboração em um artigo, seja para corrigir uma ambiguidade contida em artigo já enviado para publicação, ou ainda para discutir uma técnica recente apresentada." (Latour; Woolgar, 1997, p. 47)

\section{Percurso metodológico}

Esta pesquisa é de natureza qualitativa, uma vez que os dados coletados a partir do objeto de estudo são predominantemente descritivos. O pesquisador é o principal instrumento de produção desses dados e o significado atribuído às coisas e às situações tem atenção especial considerada no processo da pesquisa (Lüdke; André, 1986). Além disso, neste tipo de pesquisa, busca-se compreender o fenômeno estudado, considerando que todos os aspectos dos dados são relevantes e devem ser examinados por meio de uma intrínseca correlação com os referenciais teóricos que norteiam as investigações (Bauer; Gaskell; Allum, 2013).

Para atender aos objetivos desta pesquisa, adotamos como referencial teórico as considerações apresentadas por Latour e Woolgar (1997) no livro A vida de laboratório, conforme categorias descritas no tópico anterior. Essa obra foi escolhida por dar destaque, de forma minuciosa, ao cotidiano do laboratório, ao processo de produção literária, às preocupações que acompanham as escolhas e o trabalho do cientista, às questões de crédito e credibilidade dentro da ciência, às relações de credibilidade estabelecidas entre os membros da comunidade e muitos outros aspectos da prática social da ciência.

Neste estudo, analisamos alguns cartuns de Sidney Harris, os quais foram selecionados do livro A ciência ri: o melhor de 
Sidney Harris (Harris, 2007) e da página do artista: http://www. sciencecartoonsplus.com/index.php. O livro apresenta uma seleção feita por Sam Harris dos considerados melhores cartuns de Sidney que estão relacionados com a ciência em geral. Já na página, estão disponíveis para livre acesso diversos cartuns produzidos por Harris abrangendo várias temáticas e agrupados em galerias como: química, ética, educação, astronomia, negócios, biologia, computadores, economia, meio ambiente, psicologia, medicina, dentre muitos outros (Harris, 2014).

Para a análise dos cartuns, o primeiro passo foi a delimitação do corpus, cuja escolha foi norteada pelos objetivos da pesquisa. Dessa forma, para a seleção dos cartuns, adotamos como critério principal a presença de imagens de cientistas em diversas situações do cotidiano da ciência ou imagens que abordam questões ligadas ao trabalho de cientistas. Esse critério foi adotado tanto para os cartuns disponíveis no livro quanto na página do autor. Além disso, para a escolha dos cartuns disponíveis na página, optamos por fazer esse recorte apenas dentre aqueles incluídos na galeria denominada Química pelo fato de abordar várias questões ligadas à ciência e retratar algumas questões e vivências dessa área. O corpus analítico deste trabalho foi constituído por 10 desses cartuns, uma vez que, pela natureza qualitativa da pesquisa, julgamos ser um número suficiente para tecermos as considerações sobre os aspectos da sociologia da ciência que expressam.

A etapa seguinte foi constituída pelos procedimentos de análise das imagens em si, os quais foram adaptados de Penn (2013) para os objetivos de nossa pesquisa, e seguiram os seguintes passos: o inventário denotativo do cartum e a análise de significação conotativa.

O inventário denotativo correspondeu à identificação dos elementos de cada cartum por meio de anotações detalhadas sobre o traçado da imagem e sobre os textos nele incluídos. Nessa análise, foram considerados elementos como, por exemplo: o cenário no qual os personagens estão inseridos (escritório, laboratório, sala de reuniões, objetos presente no espaço físico etc.); os eventos característicos retratados no cartum; os textos (diálogos, mensagens etc.); as expressões faciais; o gênero; as vestimentas; a idade aparente dos personagens. Dessa forma, cada elemento do cartum foi dissecado em unidades menores, realizando-se uma espécie de catalogação do sentido literal do material.

A etapa seguinte foi uma análise de significação conotativa do cartum, a qual correspondeu ao estudo dos níveis de significação dos elementos identificados no procedimento anterior. Nessa etapa, buscamos compreender o que cada elemento presente no inventário denotativo conota, como esses elementos se relacionam uns com os outros na produção de sentidos e, sobretudo, quais as associações que eles podem estabelecer com referencial teórico adotado (a sociologia da ciência). Dessa forma, cada cartum foi agrupado nas categorias analíticas definidas a priori a partir da obra de Latour e Woolgar, a fim de que pudéssemos estudar que práticas da ciência são comumente expressas nesses materiais e se estes estabelecem relações com a maneira como a ciência é descrita na perspectiva teórica adotada. Em alguns casos, outros aspectos da prática da ciência que julgamos relevante na análise dos cartuns, ainda que não explicitados na obra de Latour e Woolgar, também foram considerados na interpretação dos dados.

Esse procedimento de análise foi realizado individualmente para cada cartum. Em seguida, fez-se uma análise global do corpus. Por fim, com base nos resultados, foram tecidas algumas discussões sobre o uso desse material no contexto da educação em ciências.

\section{Resultados e Discussão}

Considerando as intencionalidades desse estudo, foram selecionados alguns cartuns de Sidney Harris que pudessem colocar em destaque os contornos próprios à vida (social) da ciência descritos por Latour. A seguir, apresentamos os cartuns selecionados e os possíveis aspectos da prática da ciência que estes trazem à tona. Inicialmente é apresentada a análise de cada cartum e, em seguida, uma análise global de todos eles, evidenciando as categorias que mais se destacaram.

\section{Cartum 1}

No cartum apresentado na Figura 1, tem-se um homem mais velho dentro de um laboratório contendo equipamentos e algumas vidrarias. Aliado a esse desenho, o homem faz uso de um jaleco, representando, portanto, a imagem de um cientista em seu ambiente de trabalho. O cientista está segurando papéis e olhando com expressão de cansaço para o

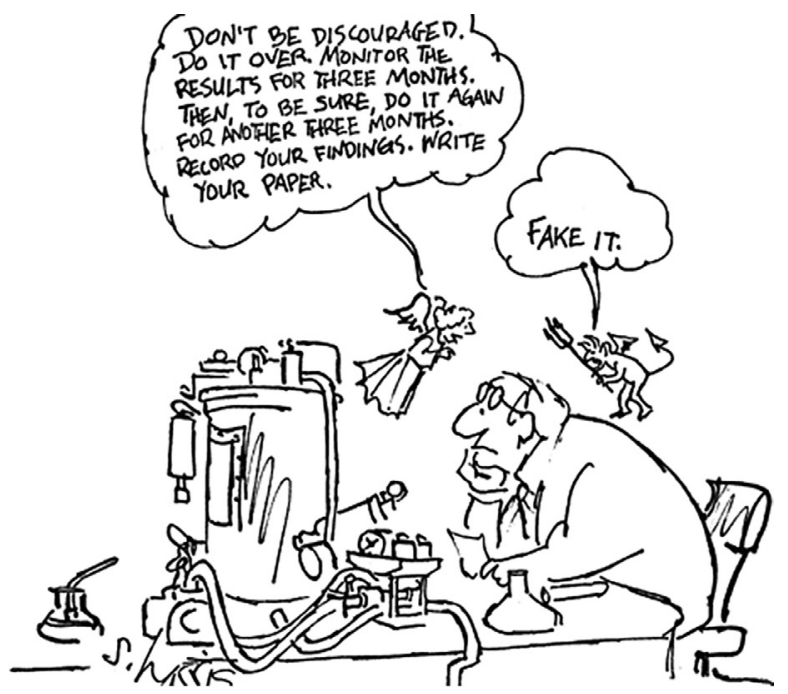

"Não desanime. Faça de novo. Monitore os resultados por três meses. Então, para ter certeza, faça novamente por mais três meses. Registre seus resultados. Escreva seu artigo."

"Falsifique."

(tradução dos autores)

Figura 1. Cartum ilustrando o dilema de um pesquisador: de um lado, esperar por todo o processo desde a produção de dados até a publicação; por outro, falsificar dados (Harris, 2014). 
equipamento. No cartum, há ainda um anjinho que fala para o cientista não desanimar, fazer novamente os experimentos e monitorar os resultados por vários meses, repetindo-os para ter certeza. Além disso, deve registrar todos os resultados e só então escrever o artigo.

Tanto as falas apresentadas pelo anjinho no cartum quanto o cenário e a expressão de preocupação ou cansaço do cientista podem evidenciar alguns dos processos que fazem parte do cotidiano da ciência. Por fim, para trazer um tom cômico, o cartunista traz a fala de um diabinho estimulando o cientista a falsificar os resultados.

Esse cartum pode remeter a um dos aspectos mais ressaltados na obra de Latour e Woolgar: a publicação de artigos como uma tarefa essencial no trabalho do cientista. Segundo os autores, os artigos chegam a ser considerados como o produto principal que saem das fábricas (os laboratórios de pesquisa). É, sobretudo, por meio das publicações que o pesquisador conquista reconhecimento da comunidade científica.

Vale ressaltar que o cartum ilustra também o uso de inscritores e o processo de produção literária no trabalho do cientista. Possibilita, portanto, discutir que desde a produção de dados, por meio dos inscritores, até a publicação de um artigo, são necessários muitos processos, pessoas envolvidas, recursos e tempo. Além disso, pelo fato de o texto enfatizar a produção de um artigo como tarefa final do cientista, o cartum mostra que o trabalho na ciência não ocorre apenas no laboratório, mas envolve a produção bibliográfica, ou seja, as preocupações e tarefas que recaem sobre o pesquisador não se limitam ao trabalho nas bancadas do laboratório.

Outro aspecto a ser mencionado neste cartum é a sátira realizada à questão da falsificação de resultados na ciência. Isso pode ser um indicativo de como a produção acadêmica é primordial para o cientista, pois é por meio dela que a comunidade científica divulga os resultados de suas pesquisas entre os pares. Por isso, quanto mais artigos publicados, mais credibilidade o cientista terá e, consequentemente, os investimentos no seu trabalho serão maiores, possibilitando novas pesquisas ou a continuidade de um projeto. A questão das fraudes na ciência, abordada por Harris, é um aspecto amplamente discutido na comunidade científica atual (Coelho, 2006), a qual traz geralmente como pano de fundo as pressões por publicações - moeda que impulsiona o ciclo de credibilidade do pesquisador e a produção de fatos.

\section{Cartum 2}

O cartum apresentado na Figura 2 ilustra um homem mais velho em um laboratório repleto de vidrarias. Este segura nas mãos um papel e conversa com um homem mais jovem. $\mathrm{O}$ cartum apresenta também um texto referente à fala do homem mais velho, o qual relata que o currículo do jovem parece ser bom e pede, então, para que ele fale de alguns de seus encantamentos. Ambos usam roupas típicas das imagens de magos ou alquimistas.

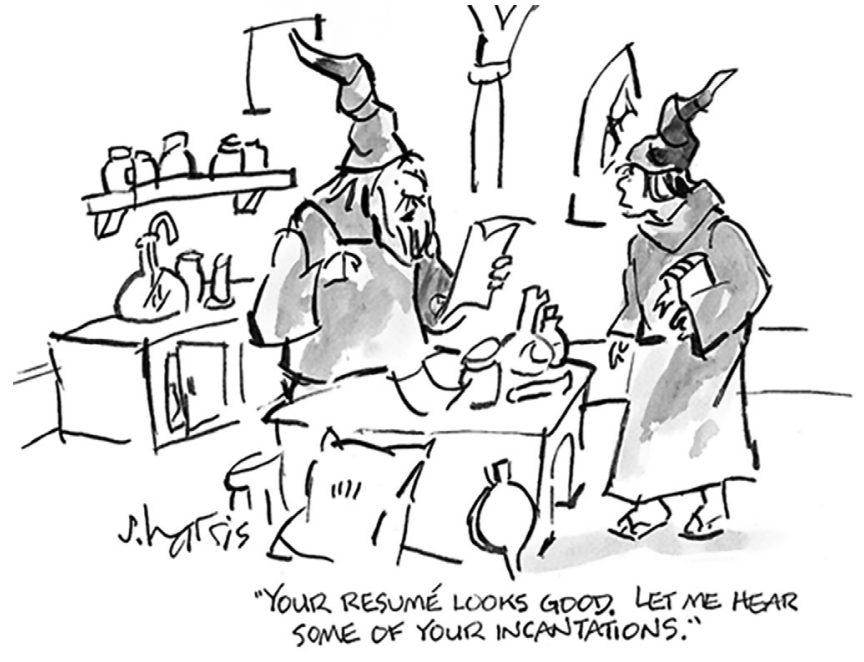

"Seu currículo parece bom. Deixe-me ouvir alguns de seus encantamentos." (tradução dos autores)

Figura 2. Cartum ilustrando a valorização do currículo do pesquisador (Harris, 2014).

Esse cartum possibilita dar destaque à importância do currículo do cientista e à maneira como os membros da comunidade científica avaliam uns aos outros e lhes atribuem credibilidade. A credibilidade do colega é, portanto, avaliada por meio desse instrumento culturalmente instituído dentro da comunidade científica.

Conforme já discutido anteriormente, a obra de Latour e Woolgar (1997) revela que o reconhecimento e prestígio do pesquisador estão diretamente ligados à sua produção acadêmica. Tal reconhecimento pode refletir-se no interesse que os outros demonstram no seu trabalho, no fato de que ele seja mais facilmente acreditado ou ouvido com maior atenção pela comunidade, que seus dados sejam mais confiáveis formando um conjunto mais digno de crédito. Dessa forma, a lista de qualificações/publicações do cientista descritas no seu currículo pode se configurar em crédito e alimentar seu ciclo de credibilidade. De acordo com os autores,

Os nomes dos coautores, os títulos dos artigos, as revistas em que foram publicados e o tamanho da lista determinam o conjunto do valor de um pesquisador. É depois da leitura do curriculum vitae e das cartas de recomendação, que dão a medida do valor de um indivíduo, que se toma a decisão de lhe atribuir um cargo, de lhe conceder subvenção, de aliciá-lo ou simplesmente colaborar com ele em um programa de pesquisa específico. (p. 238)

Outro aspecto a ser destacado nesse cartum é que as roupas dos cientistas fazem alusão à popular imagem de um alquimista, talvez usada pelo cartunista para falar de estudiosos ligados à área de química - de fato, o cartum estava inserido na galeria Química - ou ainda com a intenção de mostrar que 
o estabelecimento de critérios para valorar a credibilidade de um cientista seja algo muito antigo dentro da própria ciência.

\section{Cartum 3}

O cartum apresentado na Figura 3 ilustra um homem e uma mulher, ambos usando jalecos, conversando em um laboratório cujas bancadas estão repletas de vidrarias. Ela segura um papel nas mãos e dialoga com o homem. O cartum descreve o texto da fala da mulher, na qual ela explicita que os resultados decorrentes da adição de magnésio a sulfeto de potássio podem ser divulgado em revistas como Magnesium Journal, Potassium Review e Sulfide Studies.
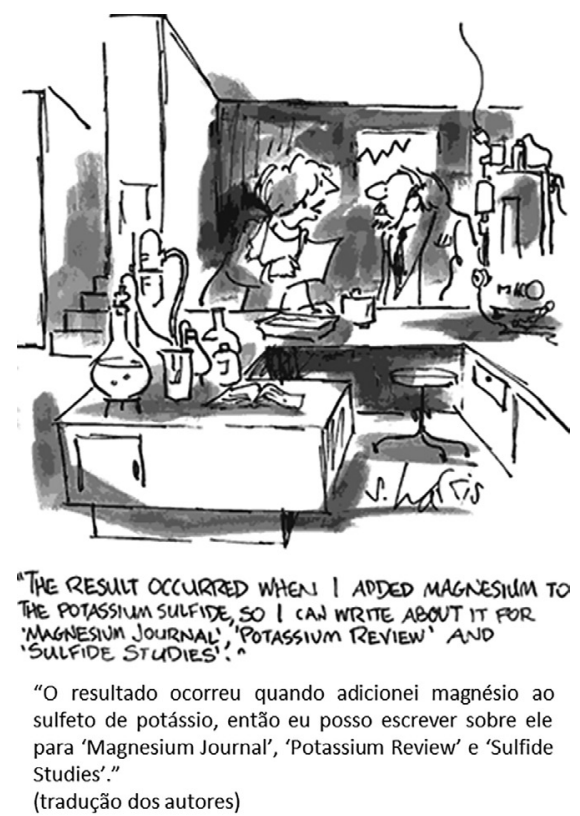

Figura 3. Cartum ilustrando a possibilidade da produção de artigos científicos em vários periódicos a partir de um resultado de pesquisa (Harris, 2014).

Uma conotação possível desse cartum é a indicação de que o resultado de um único trabalho pode ser desmembrado para gerar vários artigos para revistas científicas com foco ligeiramente distintos, gerando três publicações diferentes sobre um mesmo resultado. Isso mostra como a comunidade científica pode trabalhar com os dados produzidos, dividindo-os em vários artigos que, em conjunto, formam o histórico de todo um trabalho. Esse aspecto pode estabelecer relação direta com a importância atribuída às publicações de artigos no trabalho do cientista.

O fato de a mulher ter em mãos um papel para poder dialogar sobre os resultados com o colega também pode dar destaque ao trabalho na ciência como um processo de inscrição literária, nas qual os fatos científicos são construídos a partir de registros escritos dos dados produzidos no laboratório - seja na forma de gráficos, por exemplo, oriundos dos inscritores ou na forma de relatórios produzidos pelo corpo técnico.
Um outro aspecto que também pode ser atribuído a esse cartum é a questão da especialização do conhecimento científico. Para lidar com o grande número de informações, a comunidade científica foi se especializando cada vez mais, gerando o alto grau de especificidade do conhecimento científico que encontramos hoje. Dessa maneira, os cientistas foram se aprofundando cada vez mais em uma área da ciência e, mais adiante, em assuntos ou linhas de pesquisa dentro de uma mesma área. A especialização ocorrida nas comunidades científicas refletiu-se também nos títulos dos periódicos: surgiram periódicos cujos artigos tratam de assuntos cada vez mais delimitados. Um exemplo é o Nitric Oxide, destinado a publicar trabalhos de pesquisas relacionadas a uma molécula específica, o óxido nítrico (Oliveira; Queiroz, 2007).

\section{Cartum 4}

No cartum da Figura 4, é apresentada a imagem de dois homens com vestimentas medievais, conversando em um laboratório rodeado de vidrarias. Alguns livros e papéis estão dispostos sobre a mesa ou fixados na parede. Um dos homens usa roupas que fazem alusão a magos ou alquimistas. $\mathrm{O}$ texto que representa a fala desse homem descreve que o outro não pode replicar seu experimento, pois há um encatamento secreto que ele não revela a niguém.

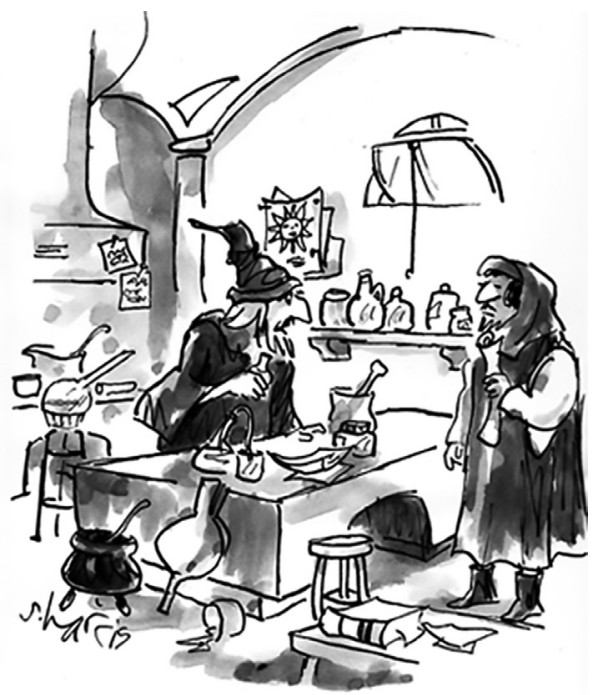

"OF COURSE YOU CAN'T REPLICATE MY EXPERMMENT. THERE'S A SECRET INCANTATION THAT YOU HAVE TO CHANT, AND I'M NOT TELUNG IT TO ANYONE."

“É claro que você não pode reproduzir meu experimento. Há um encantamento secreto que você tem que entoar, e eu não estou falando pra ninguém." (tradução dos autores)

Figura 4. Cartum ilustrando o sigilo no trabalho do cientista (Harris, 2014).

Os livros e papéis ilustrados no cartum podem ser relacionados à questão da recorrente referência à literatura como parte inerente ao trabalho na ciência.

No entanto, o aspecto que mais se destaca é o cuidado 
com o sigilo de determinadas informações da pesquisa científica. Essa prática, conforme Campanario (1999), geralmente acontece para que o pesquisador preserve seus dados durante o processo de desenvolvimento da ciência, a fim de que outro pesquisador da mesma área não utilize seus dados antes da finalização de sua pesquisa. Conforme o autor, em algumas áreas da ciência, é possível perceber uma competitividade muito grande: há uma enorme diferença entre ser primeiro e ser o segundo a publicar um novo fato, o que pode até mesmo implicar em ganhar ou perder o Prêmio Nobel. Ressalte-se, ainda, que a finalidade de tal cuidado também pode estabelecer relação com a importância atribuída às publicações no trabalho do cientista e ao investimento do pesquisador no seu ciclo de credibilidade.

Entretanto, fazendo uma pequena exploração de uma revista científica ou um banco de dados, é possível perceber que poucos estudos visam replicar estudos anteriores (Campanario, 2004). Pelo contrário, o aspecto inovador de uma pesquisa é considerado como um mérito no ambiente acadêmico. As próprias revistas acadêmicas, muitas vezes, refletem esse desejo nas orientações para os autores. Além disso, um exame cuidadoso de artigos científicos revela como pesquisadores realçam os aspectos inovadores do seu trabalho, quer na abordagem utilizada, no método seguido ou nas conclusões alcançadas (Oliveira; Queiroz, 2012).

\section{Cartum 5}

O cartum ilustrado na Figura 5 mostra uma mulher mais velha, vestindo um jaleco, segurando um papel e dirigindo-se a um homem debruçado sobre uma bancada de laboratório, sobre a qual há algumas vidrarias e papéis espalhados sobre esta. Um balão de fala ilustra a mulher reproduzindo para o colega

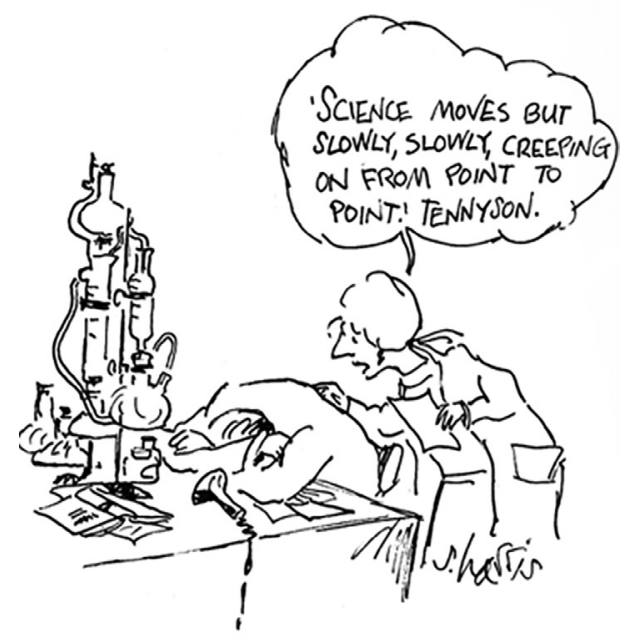

\footnotetext{
“'A ciência se move, mas lentamente, lentamente rastejando de ponto a ponto.' Tennyson." (tradução dos autores)
}

Figura 5. Cartum ilustrando que o tempo de desenvolvimento da ciência pode ser longo (Harris, 2007). a frase de um escritor (Tennylson): "a ciência se desenvolve aos poucos, lentamente, arrastando-se de ponto a ponto". Nesse cartum, mais uma vez podemos fazer referência ao trabalho na ciência como um sistema de inscrição literária.

Outra questão que pode ser discutida por meio desse cartum é a pressão pela produção do conhecimento em curto espaço de tempo. Grande parte da produção científica é baseada na demanda da sociedade, seja para desenvolver uma técnica diferenciada e econômica para substituir uma já existente, para melhorar o desempenho de um medicamento, para produzir um material sustentável a partir de extrato de planta, entre incontáveis produtos da ciência. No entanto, alguns desses produtos exigem tempo e muito teste. $\mathrm{O}$ desenvolvimento de um novo medicamento sintético, por exemplo, além de envolver vultosas somas de recursos, cerca de US\$ 350 milhões a US\$ 800 milhões, são necessários cerca de 10 a 15 anos de pesquisa (Calixto, 2003), sendo que ao final desse processo o medicamento pode ser ou não comercializado.

\section{Cartum 6}

O cartum apresentado na Figura 6, cujo título é $O$ prêmio Nobel: três caminhos. A ilustração à esquerda mostra um homem mais velho, usando óculos e jalecos, sentado em frente a uma mesa que contém papeis e um equipamento. $\mathrm{O}$ homem coloca as mãos na nuca e um balão de pesamento expressa algumas possibilidade de procedimentos experimentais que vêm à sua mente. Na ilustração do meio, há uma mulher realizando algumas anotações e debruçada sobre muitos papéis. Na ilustração à direita, um homem também mais velho e vestindo jaleco passa por uma bancada de laboratório e observa com espanto alguns frascos virados e soluções misturadas. Na bancada, também há alguns papéis.

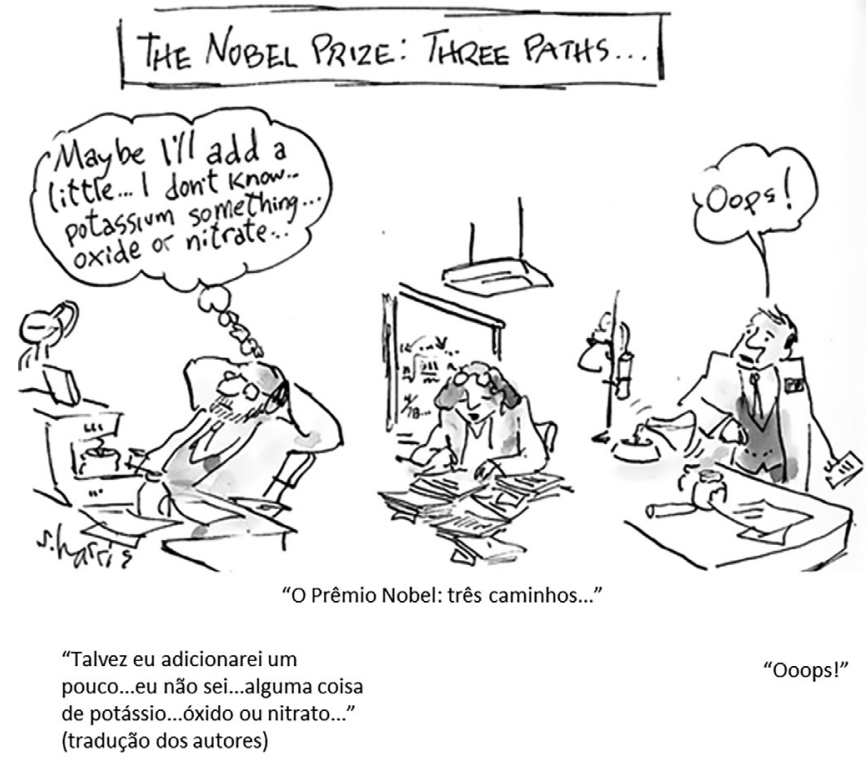

Figura 6. Cartum ilustrando alguns processos de práticas da ciência (Harris, 2014). 
O cartum incialmente faz menção a um dos sinais de um investimento bem-sucedido: o reconhecimento dentro da comunidade científica - nesse caso, por meio de um prêmio, o qual impulsiona o ciclo de credibilidade. Na ilustração, é possível perceber caminhos possíveis apresentados pelo cartunista para a obteção do prêmio: imaginação e levantamento de hipóteses que podem levar a ideias/fatos inéditos para a comunidade científica; o intenso trabalho do cientista com a literatura, seja fazendo referência a ela ou produzindo novas publicações; ou ainda situações inesperadas no laboratório que possam ser relevantes para a ciência.

Portanto, o cartum permite discutir a produção do conhecimento científico como atividade humana e o papel criativo inerente ao trabalho do pesquisador (Cachapuz et al., 2005). Cabe destacar que esse cartum possibilita também observar outros detalhes do cotidiano dos cientistas que, conforme evidenciado na obra de Latour e Woolgar (1997), vai muito além do laboratório: o trabalho nos escritórios, a inscrição literária, a produção de artigos, a leitura dos artigos publicados pelos pares que dialogam com suas pesquisas.

\section{Cartum 7}

O cartum da Figura 7 ilustra um homem com vestimentas típicas de mago ou alquimista segurando nas mãos um papel e conversando com outro homem cujas vestimentas são diferentes. No cenário ilustrado, há ainda frascos e mais alguns papéis sobre a mesa. O texto que descreve a fala do personagem dá

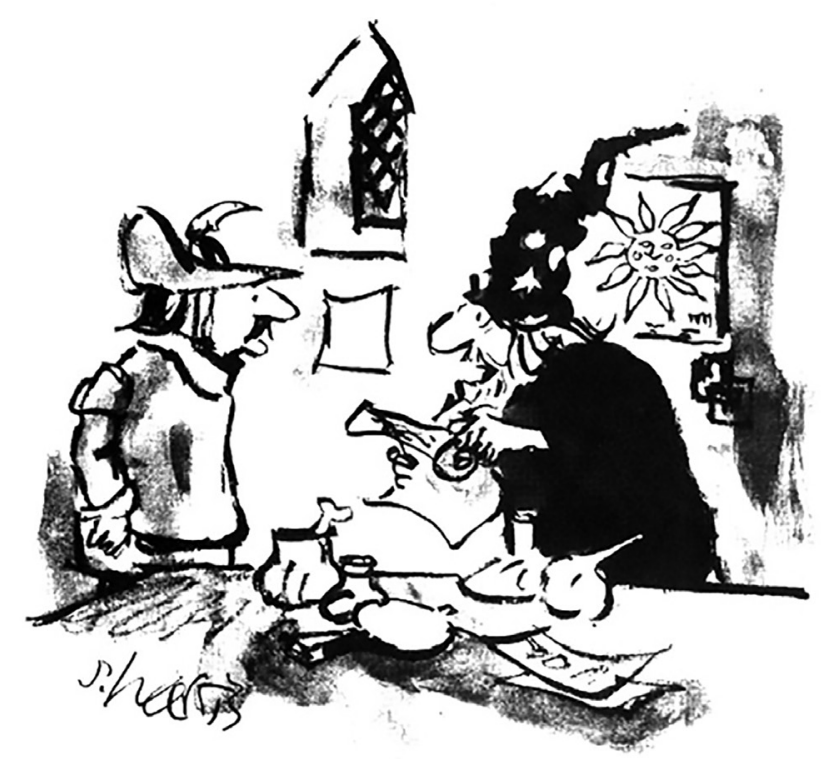

\section{"Infelizmente, este laboratório é financiado apenas pelo ouro que somos capazes de fazer a partir do chumbo."}

Figura 7. Cartum ilustrando a valorização da produção de um laboratório para obtenção financiamento (Harris, 2007). ênfase à questão das fontes de financiamento do laboratório: o próprio ouro produzido a partir do chumbo.

Alguns aspectos relevantes podem ser discutidos a partir da análise desse cartum. Primeiro, os personagens, com suas vestimentas distintas, podem representar a relação estabelecida entre membros internos e externos ao laboratório, revelando que o trabalho na ciência não envolve apenas aqueles ligados ao laboratório.

O outro aspecto de destaque é a questão do gerenciamento de recursos como prática inerente ao trabalho do cientista, o que, de certa forma, também tem implicações na manutenção do ciclo de credibilidade do pesquisador. Segundo Latour e Woolgar (1997), os cientistas se comportam como um investidor capitalista com o objetivo de obter mais lucros para investir na sua pesquisa, seja em novos equipamentos, pessoal, reagentes e até mesmo aumentando sua capacidade de produção. Para se ter investimento no trabalho, é necessário levar em consideração o efeito de retorno, a política financeira da região e recepção dos artigos publicados.

O cartum explicita ainda que o laboratório é o responsável por angariar seu próprio investimento: o financiamento vem do ouro produzido a partir do chumbo. Já no laboratório, a maior riqueza produzida pelo pesquisador é o artigo científico e é, a partir dele, que o cientista recebe auxílio financeiro, seja de agências de fomento ou até mesmo em parcerias com empresas.

\section{Cartum 8}

O cartum apresentado na Figura 8 ilustra um homem e uma mulher conversando, ambos mais velhos. Eles estão em uma sala com vários equipamentos. $\mathrm{O}$ homem está trabalhando em um desses equipamentos e parece ter expressão de tédio. No

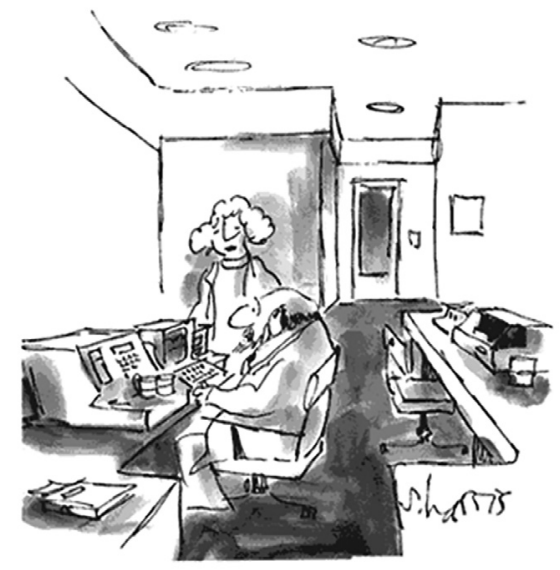

"My old lab was cluttered with test tubes, bottles, flasks, paper...Lord, how I miss it!"

Meu antigo laboratório era uma bagunça com tubos de ensaio, garrafas, frascos, artigos... Senhor, como eu sinto falta dele!"

(tradução dos autores)

Figura 8. Cartum ilustrando o trabalho de cientista no laboratório (Harris, 2014). 
texto que descreve sua fala, ele relata que seu antigo laboratório era cheio de tubos de ensaio, garrafas, frascos e artigos e que sente falta disso.

A obra de Latour e Woolgar (1997) apresenta vários detalhes do laboratório, o qual representa uma relação dos espaços ocupados pelos escritórios e o espaço das bancadas, nas quais o trabalho experimental é realizado. Esse último é muito conhecido pela presença de vidrarias, materiais e reagentes $-\mathrm{e}$, para algumas pessoas, é a imagem mais conhecida que se tem de trabalho no laboratório.

No entanto, há um local onde se encontram os inscritores, "[...] aparelhos que produzem resultados sob a forma escrita" (Latour; Woolgar, 1997, p. 44). Embora não possibilite questões de natureza mais social e relações estabelecidas entre os membros da comunidade científica, o cartum traz a possibilidade de se desmitificar o laboratório - mesmo aquela parte na qual experimentos são realizados - como local de manipulação de regentes químicos, trabalhos com produtos perigosos e explosivos, dentre tantas outras visões caricaturadas que aparecem em diversas mídias e até mesmo em materiais educativos (Kominsky; Giordan, 2002).

\section{Cartum 9}

O cartum da Figura 9 ilustra do lado esquerdo um cenário árido, sol forte, apenas areia. Neste, há um homem ajoelhado no chão como se estive escavando o local a procura de um lago. Sobre o homem, um balão de fala no qual ele suplica por água. Em cenário similar, no lado direito, também há um homem na mesma posição. Entretanto, suplicando por um espectrofotômetro.
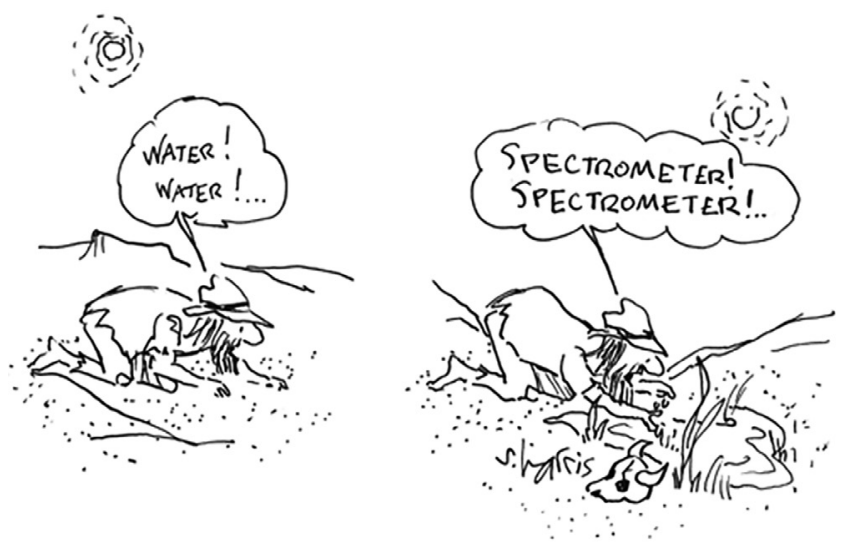

"Água! Água!"

(tradução dos autores)

“Espectrômetro! Espectrômetro!"

Figura 9. Cartum ilustrando a importância dos equipamentos para o pesquisador (Harris, 2014).

Esse cartum também dá destaque à importância dos incritores para o trabalho realizado no laboratório. Nele, o personagem deseja encontrar um espectrofotômetro tão ansiosamente quanto uma pessoa à procura de água em um ambiente árido. Ou seja, o cartum pode indicar o quanto os inscritores exercem um papel de sobrevivência para muitos daqueles que se dedicam à produção do conhecimento científico.

Vale tambem ressaltar que a aquisição de materiais e equipamentos para o laborário também é um dos elementos que impulsionam o ciclo de credibilidade do pesquisador, pois com isso, mais equipamentos, mais dados e fatos científicos poderão ser produzidos.

\section{Cartum 10}

O cartum apresentado na Figura 10 ilustra um homem e uma mulher em um laboratório repleto de equipametos. Ambos estão de jaleco e sentados de costas um para o outro, trabalhando individualmente em cada equipamento. Eles aparecem com o rosto virado um para o outro dialogando. Ela diz que está naquele ponto em que a biologia fica de fora e a química começa, enquanto ele responde dizendo que pensava que estavam no ponto onde a química fica de fora e a biologia começa.

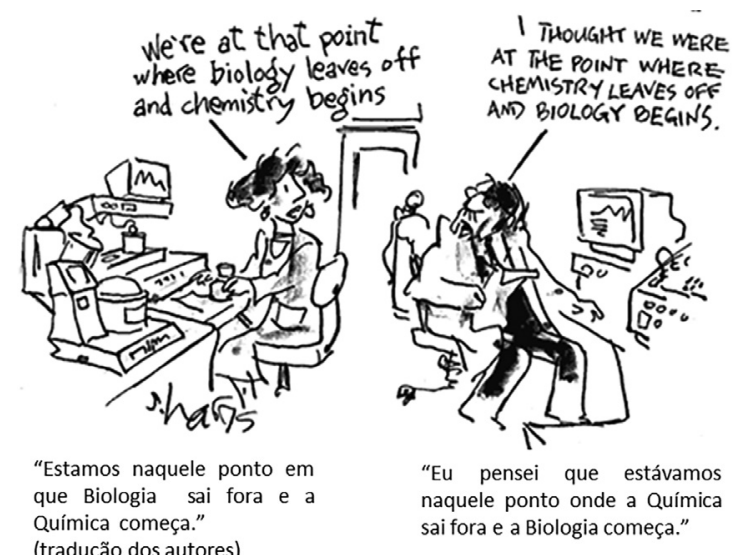

Figura 10. Cartum ilustrando o trabalho coletivo no dia a dia do laboratório (Harris, 2014).

Esse cartum dá destaque a um dos aspectos essenciais da prática da ciência: o trabalho coletivo. Essa questão é amplamente discutida por vários pesquisadores que se dedicam a estudar a natureza da ciência, os quais ressaltam a importância de se minimizar a visão de ciência como trabalho individual de um gênio detentor de todo o conhecimento (Cachapuz et al., 2005). A obra de Latour e Woolgar revela as intensas colaborações entre pesquisadores que ocorrem direta ou indiretamente na produção dos fatos. Os autores destacam que a atividade científica é governada por um sistema de troca de dádivas, em que a colaboração de conhecimentos específicos de cada pesquisador é determinante para o sucesso da produção literária.

O cartum apresentado pode colocar em destaque, portanto, a interdependência entre áreas do conhecimento e o trabalho colaborativo entre pesquisadores - prática comum na construção da ciência. As análises realizadas com artigos de divulgação científica publicados recentemente na revista Pesquisa FAPESP também evidenciaram esse aspecto coletivo na produção do conhecimento, o qual pode ocorrer por meio de parcerias diretas 
entre grupos de pesquisas ou ainda, indiretamente, por meio da literatura (Oliveira, 2013).

\section{Análise global dos cartuns}

Considerando o corpus selecionado e as análises descritas, agrupamos cada cartum nas categorias analíticas delineadas da obra de Latour e Woolgar. Os resultados dessa associação estão representado no Quadro 1, o qual nos possibilita observar que aspectos da prática da ciência, dentro da análise realizada, foram mais expressivos nos cartuns.

A questão relacionada ao trabalho na ciência como um processo de inscrição literária esteve presente em oito cartuns: a maioria apresentava ilustrações de equipamentos de laboratório ou papéis para anotações, por exemplo. A importância da inscrição literária e o quanto ela permeia o cotidiano do laboratório são aspectos bastante enfatizados na obra de Latour e Woolgar. A maior frequência com que esse aspecto aparece nos resultados também pode ter sido influenciada pelos critérios adotados na seleção dos cartuns, em que priorizamos ilustrações de cientistas em seu ambiente de trabalho.

Dois outros aspectos também apareceram de forma frequente na análise dos cartuns: o trabalho coletivo dentro da ciência e a publicação de artigos como uma tarefa essencial no trabalho do cientista. No primeiro caso, verificou-se que, em vários cartuns, o cientista não estava trabalhando ou discutindo ideias sozinho. No outro caso, a importância atribuída às publicações foi colocada pelo artista em vários cartuns, ainda que geralmente de forma muito sutil. Por outro lado, aspectos como a questão do gerenciamento de recursos e prática de fazer referência à literatura teve menor destaque dentro do corpus analisado.

Cabe ainda mencionar que, observando os cartuns aqui apresentados, podemos delinear outros aspectos relacionados à imagem geral apresentada por Harris sobre o cientista: um homem mais velho, careca e que, na maior parte do tempo, está de óculos e jaleco. Representações como essas são comuns entre aqueles que não pertencem à comunidade científica e dizem respeito à forma como a ciência vem sendo difundida e compreendida na sociedade. Conforme Osório e Pechliye (2011), essa imagem de cientista geralmente está associada a homens e velhos, inseridos em um laboratório rodeado de soluções químicas e vestindo jaleco. Acreditamos que, mesmo procurando evidenciar aspectos pouco conhecidos do trabalho do cientista, $o$ artista ainda busca apresentá-lo em suas ilustrações por representações que possam ser facilmente reconhecidas pelo grande público.

Outro ponto importante a ser destacado no trabalho do cartunista é a presença de mulheres em sua obra, as quais estão inseridas no contexto de produção da ciência e participando das discussões com os demais membros do laboratório. Vale ressaltar que esse aspecto foi observado em cinco dos dez cartuns selecionados para análise (Figuras 3, 5, 6, 8, e 10) e que tal fato não foi usado como critério para a seleção do corpus analítico. Tais observações indicam que os cartuns de Harris podem ser um recurso útil para desmistificar a ideia de que a ciência é exclusivamente masculina e fomentar debates sobre as questões de gênero na ciência.

Vale também mencionar que a análise realizada adotou como base teórica o olhar da sociologia da ciência, conforme algumas categorias delineadas a partir da obra de Latour e Woolgar (1997). Obviamente outros aspectos a respeito da natureza da ciência poderiam ser explorados sob outras perspectivas. No entanto, segundo Justi (2013, p. 5), no que se refere à natureza da ciência, "existem contribuições de diversos campos para o debate (por exemplo, sociologia, psicologia, economia, antropologia). Por isso, é essencial que pesquisadores interessados nesta temática não restrinjam seus estudos às contribuições da filosofia e da história que, apesar de muito importantes, limitam a visão sobre ciências". Dessa forma, compreendemos que a escolha da sociologia da ciência para delinear nossas análises possibilita ampliar visões sobre o trabalho do cientista, dando destaque a algumas questões contemporâneas de sua prática como currículo, publicações, credibilidade, ética, financiamento, competição, gênero, dentre outras.

Por fim, ressaltamos que os procedimentos adotados na análise dos cartuns não foram ancorados em referenciais teórico-metodológicos comumente empregados nas análises de imagens como, por exemplo, a análise semiótica. Referenciais dessa natureza possibilitariam outros olhares e interpretações do

Quadro 1. Relação das categorias analíticas delineadas a partir da obra A vida de laboratório de Latour e Woolgar (1997) e números dos cartuns (corpus analítico) associados a cada categoria.

\begin{tabular}{|l|c|}
\hline Categorias analíticas & $N^{\circ}$ do cartum \\
\hline O trabalho na ciência é coletivo & $2,3,4,5,8,10$ \\
O trabalho na ciência não ocorre apenas no laboratório & $1,6,7$ \\
O trabalho na ciência envolve um sistema de inscrição literária & $1,3,4,5,6,8,9,10$ \\
A publicação de artigos é uma tarefa essencial no trabalho do cientista & $1,2,3,4,6,7$ \\
O trabalho do cientista envolve o investimento em um ciclo de credibilidade & $2,4,6,7,9$ \\
O trabalho na ciência envolve gerenciamento de recursos & 7 \\
A referência à literatura é recorrente no trabalho do cientista & 4,6 \\
\hline
\end{tabular}


corpus. Esse fato, portanto, é uma das limitações da pesquisa apresentada neste trabalho. No entanto, consideramos que os procedimentos empregados e a relação estabelecida com o referencial teórico e suas categorias analíticas nos possibilitaram alcançar o objetivo central do estudo.

\section{Considerações Finais}

Nos cartuns analisados, observamos aspectos relacionados à vida de laboratório, a qual inclui não somente a produção de dados nas bancadas e o trabalho com os inscritores, mas também todo um esforço com a literatura para que a pesquisa seja reconhecida e aceita pelos pares. Observou-se também destaque para práticas comuns dentro da comunidade científica como a valorização das publicações, o trabalho colaborativo na produção do conhecimento, o julgamento da credibilidade de um pesquisador pelo seu currículo etc.

$\mathrm{Na}$ análise global dos cartuns, de acordo com as categorias analíticas a eles associadas, verificamos que a questão da inscrição literária, do trabalho coletivo e a importância da publicação de artigos foram os aspectos mais frequentes. Por um lado, esse resultado pode evidenciar que os cartuns de Harris colocam em destaque alguns pontos centrais do trabalho do cientista de acordo com a perspectiva teórica da sociologia da ciência de Latour e Woolgar. Por outro, é importante mencionar que os critérios empregados na seleção do corpus analítico também possam ter influenciado em tais resultados.

Acreditamos que tais aspectos não estejam presentes em muitos dos materiais - formais ou informais - destinados à educação científica e que, por esse motivo, os estudantes carecem de visões dessa natureza sobre o trabalho social da ciência. Dessa forma, os cartuns de Sidney Harris, como aqueles apresentados neste trabalho, apresentam-se como um recurso útil dentro dessa perspectiva.

A presença de mulheres é outro aspecto frequente na obra do artista, conforme ficou evidenciado nos cartuns analisados - embora esse critério não tenha sido empregado na seleção destes. Esta é também uma contribuição relevante desse material, uma vez que possibilita destacar a presença feminina na prática da ciência.

Por fim, mesmo evidenciando um fazer científico pouco conhecido da maioria das pessoas não ligadas à ciência, os cartuns de Sidney Harris ainda trazem algumas caricaturas como, por exemplo, o uso de jalecos pelos cientistas (ou roupas de alquimistas em alguns casos). Acreditamos que, como a imagem de cientista é comumente identificada por vestimentas dessa natureza, o artista procurou usá-las a fim de que o leitor pudesse reconhecer rapidamente os personagens e o universo que sua obra aborda. No entanto, esses aspectos não impedem uma possível utilização desses cartuns no contexto da educação em ciências, uma vez que as situações nas quais os personagens são expressos nas ilustrações são potencialmente ricas para discutir várias questões sobre o fazer ciência e sobre o trabalho do cientista.

\section{Agradecimentos}

À Fundação de Amparo à Pesquisa do Estado de Minas Gerais (FAPEMIG).

\section{Referências}

BATISTA, S.G. As charges de Caruso sob os vieses da interação e do ensino. Revista Philologus, v. 17, n. 51, 2011.

BAUER, M.W.; GASKELL, G.; ALLUM, N.C. Qualidade, quantidade e interesses do conhecimento. Em: BAUER, M.W.; GASKELL, G. Pesquisa qualitativa com texto, imagem e som: um manual prático. Petrópolis: Vozes, 2013. p. 17-36.

BRASIL. Ministério da Ciência e Tecnologia. Percepção pública da ciência e tecnologia: enquete 2010. Disponível em: <http://www. museudavida.fiocruz.br/media/enquete2010.pdf >. Acesso em 16 out. 2013.

Secretaria de Educação Média e Tecnológica. PCNEM Parâmetros Curriculares Nacionais para o Ensino Médio: ciências da natureza, matemática e suas tecnologias. Brasília: MEC; SEMTEC, 1999.

CACHAPUZ, A. et al. (Orgs.). A necessária renovação do ensino de ciências. São Paulo: Cortez, 2005.

CALIXTO, J.B. Biodiversidade como fonte de medicamentos. Ciência e Cultura, v. 55, n. 3, p. 37-39, 2003.

CAMPANARIO, J.M. Algunas possibilidades del artículo de investigación como recurso didáctico orientado a cuestionar ideas inadecuadas sobre la ciência. Enseñanza de las Ciencias, v. 22, n. 3, p. 365-378, 2004.

La ciência que no enseñamos. Enseñanza de las Ciencias, v. 17, n. 3, p. 397-410, 1999.

CARVALHO, A.M.P.; GIL-PÉREZ, D. Formação de professores de ciências: tendências e inovações. 7. ed. São Paulo: Cortez, 2003.

COELHO, F. Competição, sucesso e ética. Química Nova, v. 29, n. 2, p. 185, 2006.

COSTA, V.R. O cientista no imaginário popular. Revista Ciência Hoje, 19 set. 2013. Disponível em: <http://cienciahoje.uol.com.br/aloprofessor/intervalo/2013/09/o-cientista-no-imaginario-popular>. Acessado em 04 out. 2014

DÍAZ, J.A.A. Reflexiones sobre las finalidades de la enseñanza de las ciencias: educación científica para la ciudadanía. Eureka, v. 1, n. 1, p. 3-16, 2005.

GIL-PÉREZ, D.; VILCHES, A. A importância da educação científica na sociedade atual. Em: CACHAPUZ, A. et al. (Orgs.). A necessária renovação do ensino de ciências. São Paulo: Cortez, 2005, p.19-34.

HARRIS, S. A ciência ri: o melhor de Sidney Harris. São Paulo: Ed. UNESP, 2007.

Science cartoon plus: chemistry. Disponível em: <http://www. sciencecartoonsplus.com/gallery/chemistry/index.php>. Acesso em: 03 mar. 2014.

JOLY, M. Introdução à análise de imagens. Campinas: Papirus, 1996. 
JORDAN, R.; DUNCAN, R.G. Student teachers' images of science in ecology and genetics. Journal of Biological Education, v. 43, n. 2, p. 62-69, 2009.

JUSTI, R. Ensino sobre ciências: da falta de consenso aos novos desafios a serem enfrentados In: ENCONTRO NACIONAL DE PESQUISA EM EDUCAÇÃO EM CIÊNCIAS, 9, 2013. Atas... Águas de Lindóia: ABRAPEC, 2013.

KOMINSKY, L.; GIORDAN, M. Visões de ciência e de cientistas entre estudantes do ensino médio. Química Nova na Escola, n. 15, p. 11-18, 2002.

KROPF, S.P.; FERREIRA, L.O. A prática da ciência: uma etnografia no laboratório. História, Ciências, Saúde - Manguinhos, v. 3, n. 5, p. 589-597 1998.

LATOUR, B. Ciência em ação: como seguir cientistas e engenheiros sociedade afora. São Paulo: Ed. UNESP, 2000.

LATOUR, B.; WOOLGAR, S. A vida de laboratório: a produção dos fatos científicos. Rio de Janeiro: Relume Dumará, 1997.

LÜDKE, M.; ANDRÉ, M.E.D.A. Pesquisa em educação: abordagens qualitativas. São Paulo: EPU, 1986.

MENDONÇA, M.R.S. Um gênero quadro a quadro: história em quadrinhos. In: DIONISIO, A.P.; MACHADO, A.R.; BEZERRA, M.A. (Orgs.). Gêneros textuais e ensino. Rio de Janeiro: Lucerna, 2002.

MORETTI, F. Qual a diferença entre charge, cartum e quadrinhos? Disponível em: <http:// ccghumor.com.br>. Acesso em: 18 set. 2006.

OKI, M.C.M.; MORADILLO, E.F. O ensino de história da química: contribuindo para a compreensão de natureza da ciência. Ciência \& Educação, v. 14, n. 1, p. 67-88, 2008.

OLIVEIRA, J.R.S. A dinâmica da ciência em textos de divulgação científica da revista Pesquisa FAPESP. In: ENCONTRO NACIONAL DE PESQUISA EM EDUCAÇÃO EM CIÊNCIA, 9, 2013. Atas... Águas de Lindóia: ABRAPEC, 2013.

OLIVEIRA, J.R.S.; QUEIROZ, S.L. A retórica da linguagem científica: das bases teóricas à elaboração de material didático para o ensino superior de química. Química Nova, v. 35, n. 4, p. 851-857, 2012.

Comunicação e linguagem científica: guia para estudantes de química. Campinas: Átomo, 2007.

OSÓRIO, M.V.; PECHLIYE, M.M. Análise das concepções de alunos de uma escola pública em São Paulo sobre a imagem dos cientistas. In: ENCONTRO NACIONAL DE PESQUISA EM EDUCAÇÃO EM CIÊNCIAS, 8, 2011. Atas... Campinas: ABRAPEC, 2011.

PENN, G. Análise semiótica de imagens paradas. In: BAUER, M.W.; GASKELL, G. Pesquisa qualitativa com texto, imagem e som: um manual prático. Petrópolis: Vozes, 2013. p. 319-341.

REYNOL, F. Cartunista faz graça com o mundo da ciência. Ciência e Cultura, v. 60, n. 1, p. 14-15, 2008.

TANCINI, P.E.G.; HOFF, T.M.C. O mangá e a turma da Mônica jovem: processos de interculturalidade. In: SEMINÁRIO DE INICIAÇÃO CIENTÍFICA DA ESPM, 1, 2012. Anais... São Paulo: ESPM, 2012.

VIANNA, D.M.; CARVALHO, A.M.P. Bruno Latour e contribuições da antropologia da ciência: aspectos para o ensino de ciências. Ciência \& Ensino, n. 10, p. 14-19, 2001.

ZANON, D.A.V.; ALMEIDA, M.J.P.M.; QUEIROZ, S.L. Contribuições da leitura de um texto de Bruno Latour e Steve Woolgar para a formação de estudantes em um curso superior de química. Revista Electrónica de Enseñanza delas Ciencias, v. 6, n. 1, p. 56-69, 2007. 